CLINICAL STUDY

\title{
Association of risk variants for type 2 diabetes and hyperglycemia with gestational diabetes
}

\author{
Hanna Huopio*, Henna Cederberg ${ }^{1, *}$, Jagadish Vangipurapu ${ }^{2}$, Heidi Hakkarainen ${ }^{3}$, \\ Mirja Pääkkönen ${ }^{4}$, Teemu Kuulasmaa ${ }^{2}$, Seppo Heinonen ${ }^{3}$ and Markku Laakso ${ }^{1}$ \\ Department of Pediatrics, Kuopio University Hospital, Kuopio, Finland, ${ }^{1}$ Department of Medicine, Kuopio University Hospital, University of Eastern \\ Finland, 70210 Kuopio, Finland, ${ }^{2}$ Department of Medicine, University of Eastern Finland, Kuopio, Finland, ${ }^{3}$ Department of Obstetrics and Gynecology, \\ Kuopio University Hospital, Kuopio, Finland and ${ }^{4}$ Siilinjärvi Health Center, Siilinjärvi, Finland \\ (Correspondence should be addressed to M Laakso; Email: markku.laakso@kuh.fi) \\ *(H Huopio and H Cederberg contributed equally to this work)
}

\begin{abstract}
Objective: The aim of this study was to investigate the association of risk variants for type 2 diabetes (T2D) and hyperglycemia with gestational diabetes (GDM).

Design and methods: Five hundred and thirty-three Finnish women who were diagnosed with GDM and 407 controls with normal glucose tolerance during the pregnancy were genotyped for 69 singlenucleotide polymorphisms (SNPs) which have been previously verified as susceptibility risk variants for T2D and hyperglycemia. All participants underwent an oral glucose tolerance test at the follow-up study after the index pregnancy.

Results: Risk variants rs10830963 and rs1387153 of MTNR1B were significantly associated with GDM (odds ratio $(\mathrm{OR})=1.62(95 \%$ CI $1.34-1.96), P=4.5 \times 10^{-7}$ and $1.38(1.14-1.66)$, $P=7.6 \times 10^{-4}$ respectively). Both SNPs of MTNR1B were also significantly associated with elevated fasting glucose level and reduced insulin secretion at follow-up. Additionally, risk variants rs 9939609 of FTO, rs2796441 of TLE1, rs560887 of G6PC2, rs780094 of GCKR, rs7903146 of TCF7L2 and rs11708067 of ADCY5 showed nominally significant associations with GDM (OR range from 1.25 to 1.30$)$.

Conclusions: Our study suggests that GDM and T2D share a similar genetic background. Our findings also provide further evidence that risk variants of MTNR1B are associated with GDM by increasing fasting plasma glucose and decreasing insulin secretion.
\end{abstract}

European Journal of Endocrinology 169 291-297

\section{Introduction}

Gestational diabetes (GDM) is defined as abnormal glucose tolerance during pregnancy resolving after delivery. Previously published studies suggest that the prevalence of GDM is increasing, and currently affects $2-14 \%$ of all pregnancies depending on the diagnostic criteria $(1,2)$. GDM increases the risk of adverse neonatal outcomes and predicts the development of type 2 diabetes (T2D) in both the mother and the offspring $(3,4)$.

GDM and T2D share similar pathophysiology. During pregnancy, insulin resistance increases and when accompanied by impaired beta cell function, the risk of GDM increases. Similarly, peripheral insulin resistance accompanied by an insulin secretion defect leads to abnormal glucose tolerance and T2D (5) in the nonpregnant individual. In addition, GDM and T2D share several risk factors including overweight and family history of diabetes. A previous study has demonstrated that compared with women without a family history of diabetes, women with a maternal, paternal or sibling history of diabetes had greater risk of GDM (odds ratios (ORs) 3.0, 3.3 and 7.1 respectively) (6). Therefore, GDM could serve as a window to the subsequent metabolic health in women, and reflect a predisposition to developing T2D (7).

T2D has a strong genetic component. Previous studies have demonstrated that T2D is associated with genetic variation in several genes, each conferring a small increase in the risk of T2D by interacting with other diabetes-susceptibility genes, the metabolic environment of the body and lifestyle factors (8). Similarly, there is accumulating evidence that genetic factors contribute to abnormal glucose tolerance and GDM during pregnancy (9). However, knowledge regarding the genetic risk loci for GDM is still limited. The only genome-wide association study (GWAS) of GDM has been performed among Korean women and showed a strong association between risk alleles of rs10830962 MTNR1B and rs7754840 CDKAL1 and 
GDM (10). The effects sizes of the known T2D risk variants in GDM and in T2D were of similar magnitude, giving evidence that GDM and T2D share a similar genetic background (10). In a recent meta-analysis of 22 studies including 10336 GDM cases and 17445 controls, eight single-nucleotide polymorphisms (SNPs) were significantly associated with GDM (rs7903146 TCF7L2, rs10830963 MTNR1B, rs4402960 IGF2BP2, rs5219 KCNJ11, rs7754840 CDKAL1, rs2237892 and rs2237895 KCNQ1 and rs4607517 GCK) (11).

GWAS have so far identified $\sim 70$ genetic variants (SNPs) in different genes contributing to the risk of T2D or hyperglycemia $(12,13,14,15,16,17,18,19,20,21$, $22,23,24)$. To give further evidence for the hypothesis that GDM and T2D share a common genetic basis we investigated the association of these SNPs with GDM in a case-control setting of 940 Finnish women.

\section{Subjects and methods}

The study population was collected from an existing clinical pregnancy registry at the Kuopio University Hospital, Kuopio, Finland. A total of 533 previously nondiabetic women were identified who were diagnosed with GDM between the years 1989 and 2009, and 407 women with normal glucose tolerance in an oral glucose tolerance test (OGTT, $75 \mathrm{~g}$ glucose dose after overnight fasting) during pregnancy served as controls. The diagnosis of GDM was based on the following criteria: until September 2001 fasting plasma blood glucose $>4.8 \mathrm{mmol} / \mathrm{l}, 1$-h blood glucose $>10.0 \mathrm{mmol} / \mathrm{l}$ and 2 -h blood glucose $>8.7 \mathrm{mmol} / \mathrm{l}$, and since September 2001 fasting plasma glucose $>4.8 \mathrm{mmol} / \mathrm{l}$, 1-h plasma glucose $>11.2 \mathrm{mmol} / \mathrm{l}$ and 2 -h plasma glucose $>9.9 \mathrm{mmol} / \mathrm{l}$. One or more elevated values during an OGTT resulted in the diagnosis of GDM. To study the glucose tolerance after the pregnancy an OGTT was performed in all women (mean follow-up 7.2, S.D. 6.2 years). T2D at follow-up was defined as fasting plasma glucose $\geq 7.0 \mathrm{mmol} / \mathrm{l}$ or 2 -h plasma glucose $>11.0 \mathrm{mmol} / \mathrm{l}$, or antidiabetic medication started between index pregnancy and the follow-up study. Seventeen women were started on antidiabetic medication between the index pregnancy and follow-up and 15 were diagnosed with incident T2D at the follow-up.

At the follow-up study plasma glucose during OGTT was measured by enzymatic hexokinase photometric assay (Konelab Systems reagents; Thermo Fischer Scientific, Vantaa, Finland). Insulin was determined by immunoassay (ADVIA Centaur Insulin IRI no. 02230141; Siemens Medical Solutions Diagnostics, Tarrytown, NY, USA). HbA1c was measured using the HPLC assay (TOSOH G7 glycohemoglobin analyzer; Tosoh Bioscience, Inc., San Francisco, CA, USA), calibrated to Diabetes Control and Complications Trial (DCCT) standard. The trapezoidal method was used to calculate glucose area under the curve (AUC) and insulin AUC during the OGTT. Insulin sensitivity was evaluated using the Matsuda Insulin Sensitivity Index (ISI) and insulin secretion was evaluated by dividing insulin AUC during the first 30 min of an OGTT by the corresponding glucose AUC, as previously described (25).

Genotyping was performed using the Sequenom iPlex (Sequenom, Inc., San Diego, CA, USA) or the TaqMan Allelic Discrimination Assays (Applied Biosystems) for rs1111875 of HHEX, rs5219 of KCNJ11, rs231362 and rs2283228 of KCNQ1, rs10830963 of MTNR1B, and rs7578597 of THADA at the University of Eastern Finland. All SNPs were consistent with Hardy-Weinberg equilibrium at the significance level of $P>0.05$ except for rs4607517 of GCK (P=0.000006), rs10811661 of CDKN2B $(P=0.0135)$ and rs10885122 of ADRA2A $(0.0263)$. Genotyping call rate was $99.5 \%$ and error rate $0 \%$ in $5.0 \%$ of SNPs re-genotyped.

All statistical analyses were performed using SPSS 19 statistical software (SPSS). Anthropometric and biochemical variables were log-transformed to correct for their skewed distribution, when appropriate. Comparisons between the women with GDM and corresponding controls (mean, s.D.) were done using $t$-test, using logtransformed variables for $P$ values when appropriate. Allele frequencies were compared between cases and controls using Fisher's exact test. Association of SNPs with GDM was evaluated by logistic regression analysis adjusted for maternal age at index pregnancy, and results are given as ORs with their 95\% CI. $P<7.2 \times$ $10^{-4}(0.05 / 69)$ was considered as statistically significant, given the 69 SNP analyzed. OR and 95\% CI for incident T2D at follow-up were calculated using logistic regression. The SNPs significantly associated with the risk of GDM were evaluated for their effects on fasting and postprandial glycemia, insulin sensitivity (Matsuda ISI), and insulin secretion (adjusted for Matsuda ISI) at the follow-up study using linear regression (effect size B, s.e.), adjusting for maternal age and BMI at follow-up, using log-transformed variables when appropriate. Participants with T2D and taking antidiabetic medication were excluded, leaving 923 for the follow-up analysis. At follow-up, $P<1.8 \times 10^{-4}(P=0.05$ divided by 276 ) was considered as statistically significant, given the 276 tests performed (69 SNPs and four traits). The required relative risk to achieve $\geq 80 \%$ statistical power was 1.45 to 1.3 for allele frequencies between 0.1 and 0.4 .

Ethical considerations: the study was approved by the local ethics committee in Kuopio University Hospital, and it was conducted in accordance with the Helsinki Declaration.

\section{Results}

The clinical and laboratory characteristics of the study groups are presented in Table 1. Participants with GDM 
Table 1 Clinical characteristics of individuals with GDM and controls in index pregnancy and at the follow-up study.

\begin{tabular}{|c|c|c|c|}
\hline Variable & $\begin{array}{l}\text { GDM patients } \\
\text { Mean (S.D.) }\end{array}$ & $\begin{array}{l}\text { Controls } \\
\text { Mean (S.D.) }\end{array}$ & $\boldsymbol{P}$ \\
\hline Number of women & $448-533$ & $358-407$ & \\
\hline \multicolumn{4}{|l|}{ Index pregnancy } \\
\hline Age at index pregnancy (years) & $32.6(5.9)$ & $29.9(5.3)$ & $<0.001$ \\
\hline Duration of pregnancy (weeks) & $39.2(1.5)$ & $39.5(1.6)$ & 0.033 \\
\hline $\mathrm{BMI}$ in the first trimester $\left(\mathrm{kg} / \mathrm{m}^{2}\right)$ & $26.3(4.7)$ & $24.1(3.8)$ & $<0.001$ \\
\hline Birth weight of the child $(\mathrm{g})$ & $3380(560)$ & 3480 (590) & 0.059 \\
\hline \multicolumn{4}{|l|}{ Follow-up study } \\
\hline Age at follow-up study (years) & $38.1(7.1)$ & $38.9(7.0)$ & 0.117 \\
\hline Family history of diabetes (\%) & 79.9 & 71.1 & 0.004 \\
\hline Current smoker (\%) & 18.2 & 13.9 & 0.082 \\
\hline BMI $\left(\mathrm{kg} / \mathrm{m}^{2}\right)$ & $28.3(5.5)$ & $26.8(5.0)$ & $<0.001$ \\
\hline $\mathrm{HbA1c}(\%),(\mathrm{mmol} / \mathrm{mol})$ & $5.5(0.5),(37(5.5))$ & $5.4(0.3),(36(3.3))$ & $<0.001$ \\
\hline Fasting plasma glucose (mmol/l) & $5.7(0.9)$ & $5.3(0.4)$ & $<0.001$ \\
\hline 30-min plasma glucose $(\mathrm{mmol} / \mathrm{l})$ & $8.0(1.7)$ & $7.1(1.5)$ & $<0.001$ \\
\hline 2-h plasma glucose $(\mathrm{mmol} / \mathrm{l})$ & $6.1(1.7)$ & $5.5(1.3)$ & $<0.001$ \\
\hline Fasting plasma insulin (pmol//) & 71.7 (51.0) & $54.2(36.6)$ & $<0.001$ \\
\hline 30-min plasma insulin (pmol/l) & 440.5 (308.7) & $382.9(240.2)$ & 0.008 \\
\hline 2-h plasma insulin (pmol/l) & 311.9 (295.3) & 239.5 (206.2) & $<0.001$ \\
\hline Matsuda ISI & $5.7(3.2)$ & $7.2(3.7)$ & $<0.001$ \\
\hline InsAUC $_{0-30} / \mathrm{GluAUC}_{0-30}(\mathrm{pmol} / \mathrm{mmol})$ & $37.2(23.3)$ & $35.0(19.0)$ & 0.402 \\
\hline
\end{tabular}

were older than the controls (mean age at index pregnancy 32.6 years (s.D. 5.9, range 17-47) and 29.9 years (S.D. 5.3, range 16-45 years), for GDM and control groups respectively. In the follow-up study after the pregnancy they had higher HbAlc, glucose and insulin levels during an OGTT and were more insulin resistant than control subjects. No difference in insulin secretion was observed.

Table 2 reports association of 69 SNPs studied with GDM. SNP rs10830963 of MTNR1B was significantly associated with GDM (OR 1.62 (95\% CI 1.34-1.96), $P=1.3 \times 10^{-7}$ ) adjusted for age at GDM pregnancy. In addition, rs1387153 of MTNR1B was significantly associated with GDM (1.38 (1.14-1.66), $\left.P=3.6 \times 10^{-4}\right)$. Furthermore, rs4737009 $(P=0.002)$ and rs516946 $(P=0.0499)$ of ANK1, rs9939609 of FTO $(P=0.006)$, rs2796441 of TLE1 $(P=0.014)$, rs12571751 of ZMIZ1 $(P=0.007)$, rs560887 of G6PC2 $(P=0.026)$, rs780094 of GCKR $(P=0.028)$, rs7903146 of TCF7L2 $(P=0.016)$ and rs11708067 of ADCY5 $(P=0.029)$ showed nominally significant associations with GDM (ORs between 0.74 and 1.38) even after the adjustment for maternal age at index pregnancy. Mean risk allele frequencies for GDM and control groups are given in Supplementary Table 1, see section on supplementary data given at the end of this article.

A total of 32 women had T2D at the follow-up study, of whom 30 were from the GDM and two were from the control group. GDM was strongly associated with the development of T2D after the pregnancy (OR 12.2, 95\% CI 2.9-51.2). We subsequently studied the association of SNPs having significant or nominally significant association with GDM with fasting and 2-h glucose levels, insulin sensitivity and insulin secretion in an OGTT performed after the pregnancy (Table 3). Risk alleles of rs10830963 and rs1387153 of MTNR1B $(P=9.5 \times$ $10^{-12}$ and $P=4.1 \times 10^{-5}$ respectively), and rs560887 of G6PC2 $(P=0.001)$ were associated with elevated fasting glucose level and the risk allele of rs11708067 of $A D C Y 5$ with elevated 2-h glucose level $(P=0.008$, all after the adjustment for age and BMI at follow-up). The glucose-increasing minor alleles of rs10830963 and rs1387153 of MTNR1B were associated with impaired first-phase insulin secretion at follow-up after the adjustment for age and BMI and Matsuda ISI $\left(P=3.9 \times 10^{-6}\right.$ and $P=2.0 \times 10^{-5}$ respectively). The SNPs associated with the risk of GDM were not associated with insulin sensitivity at follow-up. Additional adjustment for the diabetes status during the index pregnancy (belonging to GDM or control group) somewhat attenuated, but did not abolish the associations of MTNR1B rs10830963 and rs1387153 with FPG $\left(P=1.1 \times 10^{-8}\right.$ and $P=0.001$ respectively $)$ and insulin secretion at follow-up $\left(P=2.7 \times 10^{-4}\right.$ and $P=3.8 \times 10^{-4}$ respectively).

\section{Discussion}

Previous prospective population-based studies have shown that a history of GDM considerably increases the risk of T2D. This is not unexpected since these two conditions share similar environmental and lifestyle risk factors (such as obesity, unhealthy diet and physical inactivity), and pathophysiology, including increased insulin resistance and impaired insulin secretion (7). There is limited but increasing evidence suggesting that similar genetic risk variants which predispose to $\mathrm{T} 2 \mathrm{D}$ 
Table 2 Association of known risk gene variants for T2D and hyperglycemia with GDM.

\begin{tabular}{|c|c|c|c|c|c|c|}
\hline SNP & Gene & Alleles & OR & $95 \% \mathrm{Cl}$ & $P$ & $\boldsymbol{P}^{*}$ \\
\hline rs10830963 & MTNR1B & $C / G$ & 1.62 & $1.34-1.96$ & $4.5 \times 10^{-7}$ & $1.3 \times 10^{-7}$ \\
\hline rs 1387153 & MTNR1B & $\mathrm{C} / \overline{\mathrm{T}}$ & 1.38 & $1.14-1.66$ & $7.6 \times 10^{-4}$ & $3.6 \times 10^{-4}$ \\
\hline rs4737009 & Ank1 & $\mathrm{G} / \overline{\mathrm{A}}$ & 0.74 & $0.61-0.91$ & 0.004 & 0.002 \\
\hline rs9939609 & FTO & $T / \bar{A}$ & 1.28 & $1.06-1.54$ & 0.011 & 0.006 \\
\hline rs12571751 & $Z M I Z 1$ & $A / \bar{G}$ & 0.80 & $0.67-0.96$ & 0.016 & 0.007 \\
\hline rs2796441 & TLE1 & $\overline{\mathrm{G}} / \mathrm{A}$ & 1.27 & $1.06-1.54$ & 0.011 & 0.014 \\
\hline rs7903146 & TCF7L2 & $\overline{\mathrm{C}} / \mathrm{T}$ & 1.30 & $1.03-1.64$ & 0.028 & 0.016 \\
\hline rs560887 & G6PC2 & $\mathrm{C} / \overline{\mathrm{T}}$ & 1.28 & $1.05-1.56$ & 0.017 & 0.026 \\
\hline rs780094 & GCKR & $\overline{\mathrm{C}} / \mathrm{T}$ & 1.25 & $1.03-1.51$ & 0.027 & 0.028 \\
\hline rs11708067 & $A D C Y 5$ & $\overline{\mathrm{A}} / \mathrm{G}$ & 1.29 & $1.00-1.67$ & 0.055 & 0.029 \\
\hline rs516946 & ANK1 & $\overline{\mathrm{C}} / \mathrm{T}$ & 0.80 & $0.63-0.996$ & 0.047 & 0.050 \\
\hline rs7578597 & THADA & $\bar{T} / \mathrm{C}$ & 0.64 & $0.39-1.04$ & 0.072 & 0.060 \\
\hline rs1111875 & HHEX & $\overline{\mathrm{C}} / \mathrm{T}$ & 0.86 & $0.71-1.03$ & 0.107 & 0.067 \\
\hline rs7034200 & GLIS3 & $\overline{\mathrm{C}} / \mathrm{A}$ & 1.11 & $0.92-1.35$ & 0.274 & 0.09 \\
\hline rs13266634 & SLC $30 A 8$ & $\mathrm{C} / \overline{\mathrm{T}}$ & 0.85 & $0.70-1.02$ & 0.080 & 0.105 \\
\hline rs 4457053 & ZBED3 & $\overline{\mathrm{A}} / \mathrm{G}$ & 1.23 & $0.99-1.54$ & 0.061 & 0.116 \\
\hline rs7578326 & IRS1 & $A / \bar{G}$ & 1.13 & $0.94-1.37$ & 0.201 & 0.12 \\
\hline rs896854 & TP53INP1 & $\overline{\mathrm{C}} / \mathrm{T}$ & 1.12 & $0.93-1.34$ & 0.226 & 0.133 \\
\hline rs5945326 & DUSPY & $\mathrm{A} / \overline{\mathrm{G}}$ & 1.12 & $0.92-1.38$ & 0.262 & 0.159 \\
\hline rs282587 & ATP11A & $\overline{\mathrm{A}} / \mathrm{G}$ & 1.17 & $0.90-1.51$ & 0.240 & 0.189 \\
\hline rs2191349 & $D G K B$ & $\mathrm{G} / \bar{T}$ & 1.15 & $0.96-1.39$ & 0.139 & 0.196 \\
\hline rs552976 & $A B C B 11 / G 6 P C 2$ & $\mathrm{G} / \overline{\mathrm{A}}$ & 1.15 & $0.94-1.40$ & 0.166 & 0.210 \\
\hline rs7754840 & CDKAL1 & $\mathrm{G} / \mathrm{C}$ & 1.14 & $0.94-1.38$ & 0.179 & 0.210 \\
\hline rs972283 & KLF14 & $\mathrm{G} / \overline{\mathrm{A}}$ & 1.04 & $0.87-1.25$ & 0.674 & 0.220 \\
\hline rs340874 & PROX1 & $\bar{T} / \mathrm{C}$ & 1.10 & $0.91-1.33$ & 0.327 & 0.229 \\
\hline rs7202877 & BCAR1 & $\mathrm{T} / \overline{\mathrm{G}}$ & 1.15 & $0.90-1.48$ & 0.287 & 0.242 \\
\hline rs231362 & KCNQ1 & $\overline{\mathrm{G}} / \mathrm{A}$ & 1.12 & $0.93-1.35$ & 0.229 & 0.274 \\
\hline rs7957197 & HNF1A & $\bar{T} / \mathrm{A}$ & 0.92 & $0.74-1.15$ & 0.471 & 0.302 \\
\hline rs243021 & $B C L 11 A$ & $\overline{\mathrm{G}} / \mathrm{A}$ & 1.14 & $0.95-1.37$ & 0.169 & 0.326 \\
\hline rs13389219 & GRB14 & $\mathrm{C} / \overline{\mathrm{T}}$ & 1.12 & $0.92-1.36$ & 0.267 & 0.343 \\
\hline rs12454712 & $B C L 2$ & $\bar{T} / \mathrm{C}$ & 1.10 & $0.91-1.31$ & 0.351 & 0.362 \\
\hline rs 4402960 & IGF2BP2 & $\overline{\mathrm{G}} / \mathrm{T}$ & 1.13 & $0.93-1.38$ & 0.218 & 0.365 \\
\hline rs10923931 & NOTCH2 & $\mathrm{G} / \bar{T}$ & 1.17 & $0.89-1.52$ & 0.261 & 0.375 \\
\hline rs10012946 & WFS1 & $\mathrm{C} / \overline{\mathrm{T}}$ & 0.94 & $0.78-1.13$ & 0.511 & 0.392 \\
\hline rs5219 & KCNJ11 & $\mathrm{C} / \overline{\mathrm{T}}$ & 0.98 & $0.81-1.17$ & 0.789 & 0.425 \\
\hline rs11634397 & ZFAND6 & $\mathrm{G} / \bar{A}$ & 0.89 & $0.74-1.07$ & 0.22 & 0.431 \\
\hline rs16926246 & HK1 & $\overline{\mathrm{C}} / \mathrm{T}$ & 1.26 & $0.86-1.84$ & 0.239 & 0.462 \\
\hline rs459193 & ANKRD55 & $\overline{\mathrm{G}} / \mathrm{A}$ & 1.02 & $0.84-1.24$ & 0.856 & 0.469 \\
\hline rs1799884 & GCK & $\overline{\mathrm{C}} / \mathrm{T}$ & 1.14 & $0.85-1.53$ & 0.387 & 0.525 \\
\hline rs10885122 & ADRA2A & $\mathrm{G} / \bar{T}$ & 1.05 & $0.83-1.33$ & 0.685 & 0.547 \\
\hline rs12970134 & $M C 4 R$ & $\overline{\mathrm{G}} / \mathrm{A}$ & 0.94 & $0.74-1.19$ & 0.586 & 0.563 \\
\hline rs10842994 & KLHDC5 (KLHL42) & $\mathrm{C} / \overline{\mathrm{T}}$ & 0.96 & $0.75-1.22$ & 0.714 & 0.578 \\
\hline rs2283228 & $K C N Q 1$ & $\overline{\mathrm{A}} / \mathrm{C}$ & 0.95 & $0.65-1.39$ & 0.792 & 0.590 \\
\hline rs7961581 & TSPAN8 & $\bar{T} / \mathrm{C}$ & 0.93 & $0.74-1.16$ & 0.495 & 0.591 \\
\hline rs10770141 & $T H / I N S$ & $\mathrm{G} / \overline{\mathrm{A}}$ & 1.07 & $0.88-1.31$ & 0.484 & 0.599 \\
\hline rs11071657 & FAM148B (C2CD4B) & $\mathrm{A} / \overline{\mathrm{G}}$ & 1.07 & $0.88-1.30$ & 0.515 & 0.602 \\
\hline rs7501939 & HNF1B & $\overline{\mathrm{C}} / \mathrm{T}$ & 0.95 & $0.78-1.17$ & 0.639 & 0.607 \\
\hline rs1408272 & HFE & $\mathrm{T} / \overline{\mathrm{G}}$ & 0.85 & $0.54-1.33$ & 0.477 & 0.657 \\
\hline rs 4607517 & $G C K$ & $\mathrm{G} / \mathrm{A}$ & 1.1 & $0.80-1.51$ & 0.572 & 0.678 \\
\hline rs3794991 & GATAD2A & $\mathrm{C} / \overline{\mathrm{T}}$ & 1.00 & $0.68-1.47$ & 0.997 & 0.682 \\
\hline rs7177055 & HMG2OA & $\mathrm{A} / \overline{\mathrm{G}}$ & 1.00 & $0.83-1.22$ & 0.972 & 0.723 \\
\hline rs1801282 & PPARG & $\overline{\mathrm{C}} / \mathrm{G}$ & 0.93 & $0.73-1.20$ & 0.578 & 0.731 \\
\hline rs10811661 & CDKN2B & $\overline{\mathrm{T}} / \mathrm{C}$ & 1.09 & $0.85-1.40$ & 0.487 & 0.743 \\
\hline rs11605924 & CRY2 & $\overline{\mathrm{A}} / \mathrm{C}$ & 0.99 & $0.82-1.18$ & 0.881 & 0.747 \\
\hline rs 174550 & FADS1 & $\bar{T} / \mathrm{C}$ & 1.04 & $0.87-1.26$ & 0.652 & 0.780 \\
\hline rs 4607103 & ADAMTS9 & $\overline{\mathrm{C}} / \mathrm{T}$ & 1.00 & $0.82-1.23$ & 0.967 & 0.784 \\
\hline rs7944584 & $M A D D$ & $\overline{\mathrm{A}} / \mathrm{T}$ & 1.00 & $0.79-1.28$ & 0.972 & 0.803 \\
\hline rs10423928 & GIPR & $\bar{T} / A$ & 1.02 & $0.81-1.28$ & 0.885 & 0.804 \\
\hline rs 4925115 & SREBF1 & $\mathrm{G} / \overline{\mathrm{A}}$ & 1.01 & $0.83-1.22$ & 0.949 & 0.808 \\
\hline rs2612067 & HMGA2 & $\mathrm{T} / \overline{\mathrm{G}}$ & 1.02 & $0.72-1.45$ & 0.909 & 0.830 \\
\hline rs8042680 & PRC1 & $\mathrm{C} / \mathrm{A}$ & 1.05 & $0.87-1.28$ & 0.614 & 0.863 \\
\hline rs11920090 & $S L C 2 A 2$ & $\mathrm{~T} / \overline{\mathrm{A}}$ & 0.97 & $0.74-1.27$ & 0.803 & 0.877 \\
\hline rs12779790 & $C D C 123$ & $\overline{\mathrm{A}} / \mathrm{G}$ & 0.97 & $0.77-1.22$ & 0.786 & 0.885 \\
\hline rs1046896 & FN3K & $\mathrm{C} / \mathrm{T}$ & 0.94 & $0.77-1.16$ & 0.580 & 0.897 \\
\hline rs13292136 & CHCHD9 (CHCHD2P9) & $\mathrm{C} / \overline{\mathrm{T}}$ & 0.91 & $0.70-1.19$ & 0.484 & 0.900 \\
\hline rs 17271305 & VPS13C & $\overline{\mathrm{G}} / \mathrm{A}$ & 1.02 & $0.85-1.23$ & 0.813 & 0.904 \\
\hline rs864745 & JAZF1 & $\overline{\mathrm{C}} / \mathrm{T}$ & 0.95 & $0.79-1.14$ & 0.591 & 0.906 \\
\hline rs2779116 & SPTA1 & $\mathrm{c} / \overline{\mathrm{T}}$ & 0.98 & $0.80-1.19$ & 0.823 & 0.946 \\
\hline rs10401969 & SUGP1/CILP2 & $\mathrm{T} / \overline{\bar{C}}$ & 1.07 & $0.72-1.59$ & 0.746 & 0.981 \\
\hline
\end{tabular}

Alleles major/minor, risk allele underlined. OR $(95 \% \mathrm{Cl})$ calculated as per risk allele using logistic regression. $P^{\star}$ adjusted for maternal age at the $\mathrm{GDM}$ pregnancy. Significant $P$ values $\left(P<7.2 \times 10^{-4}\right)$ after the Bonferroni adjustment for multiple testing (for 69 SNPs and one trait) are given in bold and underlined. Significant $P$ values are given in bold. 


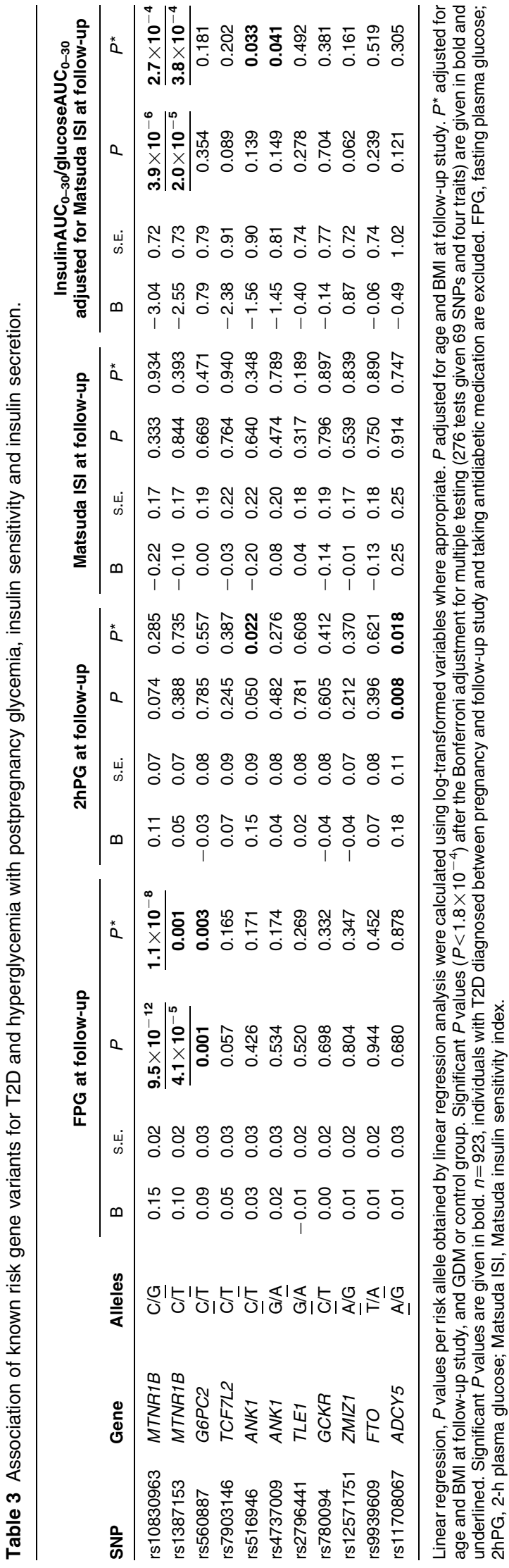

also contribute to the risk of GDM (8). In the present study we investigated the association of all 69 thus far published confirmed risk variants for T2D or hyperglycemia with GDM in Finns. Our study showed that several risk SNPs for T2D or hyperglycemia were also associated with GDM, giving further evidence that GDM and T2D share a similar genetic background.

The only GWAS published so far on risk variants for GDM reported significant associations of rs10830962 of MTNR1B (OR 1.47, $P=5.02 \times 10^{-7}$ ) and rs7754840 of CDKAL1 (OR 1.71, P=2.15 $\times 10^{-11}$ ) with GDM in Korean women (10). The effect of MTNR1B risk variants on glucose levels during pregnancy has also been found in Greek (26) and Chinese (27) women with GDM. We confirmed the association of MTNR1B with GDM in Finns as rs1083092 and rs1387153 of MTNR1B were significantly associated with GDM in our study $\left(P=1.3 \times 10^{-7}\right.$ and $P=3.6 \times 10^{-4}$ respectively). Both of these SNPs of MTNR1B were significantly associated with fasting glucose levels, as previously reported also in patients with T2D (14). The glucoseincreasing minor alleles of both SNPs of MTNR $1 B$ were also associated with impaired insulin secretion, with no effect on insulin sensitivity. Melatonin, which mediates its effects through melatonin receptors MTNR1A and MTNR1B, is best known as a regulator of seasonal and circadian rhythms (28). Carriers of the risk genotypes exhibit increased expression of MTNR1B in pancreatic $\beta$ cells which leads to impaired insulin secretion. In a very recent meta-analysis including a total of $10336 \mathrm{GDM}$ cases and 17445 controls, eight T2D risk SNPs were significantly associated with GDM (rs7903146 of TCF7L2, rs10830963 of MTNR1B, rs4402960 of IGF2BP2, rs5219 of KCNJ11, rs7754840 of CDKAL1, rs2237892 and rs2237895 of KCNQ1 and rs4607517 of GCK) (11).

The other risk variant detected in a previous Korean GWAS, rs7754840 of CDKAL1 (10), was not significantly associated with GDM in our study (OR 1.14, $P=0.210$ after adjustment for maternal age), although a trend was observed in the same direction. The lack of statistical significance is probably due to a limited number of subjects included in our study. Unexpectedly, the two T2D risk variants rs4737009 and rs516946 of ANK1 gene and rs12571751 of ZMIZ1 gene showed a nominally significant protective effect on GDM risk in our study, whereas in previous studies these two SNPs have increased the risk of T2D (23).

SNP rs7903146 of TCF7L2, the most significant risk variant for T2D reported to date (29), was nominally associated with GDM (OR 1.30, $P=0.016)$ in our study. In previous studies rs7903146 of TCF7L2 has increased the risk of GDM by $44-49 \%(30,31)$. Furthermore, previous studies have indicated that SNPs of TCF7L2 increase the risk of T2D by reducing insulin secretion (32).

FTO has been reported to be associated with obesity and therefore this gene indirectly contributes to the risk 
of T2D (21). We also found that rs9939609 of FTO was associated with the risk of GDM (OR 1.28, $P=0.006$ ) which is expected as obesity is a well-known risk factor of GDM (33). Risk variants rs560887 of TLE1, rs560887 of G6PC2 and rs780094 of GCKR have not been associated with GDM in previous studies, but in our study these variants were nominally associated with GDM (ORs 1.27, 1.28 and 1.25 respectively). G6PC2 encodes glucose-6-phosphatase 2 (G6PC2) which is involved in the terminal step of the gluconeogenic and glycogenolytic pathways, and regulates fasting plasma glucose levels (34). In agreement with previous studies, rs560887 of G6PC2 was nominally associated with fasting glucose in our follow-up study as well as with GDM. GCKR encodes the glucokinase regulatory protein, and SNPs at the GCKR locus have been associated with fasting glycemia and the risk of T2D $(35,36)$.

The limitation of our study is quite a small sample size. We had only modest statistical power to demonstrate statistically significant associations of gene variants with GDM. Furthermore, the diagnostic criteria of GDM vary worldwide which makes it difficult to compare results across different populations.

In conclusion, our study shows that several gene variants increasing the risk of T2D and hyperglycemia are also associated with GDM, suggesting a common genetic background for these two conditions. Risk variants of MTNR1B had the most significant associations with GDM in Finnish women. We also demonstrated that these variants increased fasting plasma glucose and decreased insulin secretion.

\section{Supplementary data}

This is linked to the online version of the paper at http://dx.doi.org/10. 1530/EJE-13-0286.

\section{Declaration of interest}

The authors declare that there is no conflict of interest that could be perceived as prejudicing the impartiality of the research reported.

\section{Funding}

This work was supported by the Academy of Finland (M Laakso), the Finnish Diabetes Research Foundation (H Huopio, M Laakso), the Finnish Cardiovascular Research Foundation (M Laakso), the Strategic Research Funding from the University of Eastern Finland, Kuopio, Finland (M Laakso), Maud Kuistila Foundation (H Huopio), Finnish Cultural Foundation, North Savo Regional Fund (H Huopio), EVO grant 5263 from the Kuopio University Hospital (M Laakso) and EVO grant from the Kuopio University Hospital (H Huopio).

\section{Author contribution statement}

H Huopio designed the study, collected and researched the data and wrote the manuscript. H Cederberg researched the data and wrote the manuscript. J Vangipurapu researched the data and reviewed/edited the manuscript. $\mathrm{H}$ Hakkarainen contributed to discussion and reviewed/edited the manuscript. M Pääkkönen designed the study, collected the data and reviewed/edited the manuscript. T Kuulasmaa performed genotyping and reviewed/edited the manuscript. $S$ Heinonen designed the study, collected the data and reviewed/edited the manuscript. M Laakso designed the study, contributed to discussion and reviewed/edited the manuscript, is the guarantor of this work and, as such, had full access to all the data in the study and takes responsibility for the integrity of the data and the accuracy of the data analysis.

\section{References}

1 Metzger BE. Summary and recommendation of the Third International Workshop-Conference on Gestational Diabetes Mellitus. Diabetes 199140 197-201. (doi:10.2337/diabetes.40.2.197)

2 Jovanovic L \& Pettitt DJ. Gestational diabetes mellitus. Journal of the American Medical Association 2001286 2516-2518. (doi:10.1001/ jama.286.20.2516)

3 Löbner K, Knopff A, Baumgarten A, Mollenhauer U, Marienfeld S, Garrido-Franco M, Bonifacio E \& Ziegler AG. Predictors of postpartum diabetes in women with gestational diabetes mellitus. Diabetes 200655 792-797. (doi:10.2337/diabetes.55.03.06. db05-0746)

4 Bush NC, Chandler-Laney PC, Rouse DJ, Granger WM, Oster RA \& Gower BA. Higher maternal gestational glucose concentration is associated with lower offspring insulin sensitivity and altered $\beta$-cell function. Journal of Clinical Endocrinology and Metabolism 201196 E803-E809. (doi:10.1210/jc.2010-2902)

5 Buchanan TA. Pancreatic B-cell defects in gestational diabetes: implications for pathogenesis and prevention of type 2 diabetes. Journal of Clinical Endocrinology and Metabolism 2001 86 989-993. (doi:10.1210/jc.86.3.989)

6 Kim C, Liu T, Valdez R \& Beckles GL. Does frank diabetes in first-degree relatives of a pregnant women affect the likelihood of her developing gestational diabetes mellitus or nongestational diabetes? American Journal of Obstetrics and Gynecology 2009201 576.e1-576.e6. (doi:10.1016/j.ajog.2009.06.069)

7 Robitaille J \& Grant AM. The genetics of gestational diabetes mellitus: evidence for relationship with type 2 diabetes mellitus. Genetics in Medicine 200810 240-250. (doi:10.1097/GIM. Ob013e31816b8710)

8 McCarthy MI. Genomics, type 2 diabetes, and obesity. New England Journal of Medicine $2010 \quad 363 \quad 2339-2350$. (doi:10.1056/ NEJMra0906948)

9 Watanabe RM. Inherited destiny? Genetics and gestational diabetes mellitus. Genome Medicine 20113 18. (doi:10.1186/ gm232)

10 Kwak SH, Kim SH, Cho YM, Go MJ, Cho YS, Choi SH, Moon MK, Jung HS, Shin HD, Kang HM et al. A genome-wide association study of gestational diabetes mellitus in Korean women. Diabetes 201261 531-541. (doi:10.2337/db11-1034)

11 Mao H, Li Q \& Gao S. Meta-analysis of the relationship between common type 2 diabetes risk gene variants with gestational diabetes mellitus. PLOS ONE 20127 e45882. (doi:10.1371/ journal.pone.0045882)

12 Scott LJ, Mohlke KL, Bonnycastle LL, Willer CJ, Li Y, Duren WL, Erdos MR, Stringham HM, Chines PS, Jackson AU et al. A genomewide association study of type 2 diabetes in Finns detects multiple susceptibility variants. Science 2007316 1341-1345. (doi:10.1126/ science.1142382)

13 Diabetes Genetics Initiative of Broad Institute of Harvard and MIT, Lund University, and Novartis Institutes of BioMedical Research, Saxena R, Voight BF, Lyssenko V, Burtt NP, de Bakker PI, Chen H, Roix JJ, Kathiresan S, Hirschhorn JN et al. Genome-wide association analysis identifies loci for type 2 diabetes and triglyceride levels. Science 2007316 1331-1336. (doi:10.1126/ science.1142358) 
14 Prokopenko I, Langenberg C, Florez JC, Saxena R, Soranzo N, Thorleifsson G, Loos RJ, Manning AK, Jackson AU, Aulchenko Y et al. Variants in MTNR1B influence fasting glucose levels. Nature Genetics 200941 77-81. (doi:10.1038/ng.290)

15 Lyssenko V, Nagorny CL, Erdos MR, Wierup N, Jonsson A, Spégel P, Bugliani M, Saxena R, Fex M, Pulizzi N et al. Common variant in MTNR1B associated with increased risk of type 2 diabetes and impaired early insulin secretion. Nature Genetics 200941 77-81. (doi:10.1038/ng.288)

16 Zeggini E, Scott LJ, Saxena R, Voight BF, Marchini JL, Hu T, de Bakker PI, Abecasis GR, Almgren P, Andersen G et al. Metaanalysis of genome-wide association data and large-scale replication identifies additional susceptibility loci for type 2 diabetes. Nature Genetics 200840 638-645. (doi:10.1038/ng.120)

17 Dupuis J, Langenberg C, Prokopenko I, Saxena R, Soranzo N, Jackson AU, Wheeler E, Glazer NL, Bouatia-Naji N, Gloyn AL et al. New genetic loci implicated in fasting glucose homeostasis and their impact on type 2 diabetes risk. Nature Genetics $2010 \mathbf{4 2}$ 105-116. (doi:10.1038/ng.520)

18 Saxena R, Hivert MF, Langenberg C, Tanaka T, Pankow JS, Vollenweider P, Lyssenko V, Bouatia-Naji N, Dupuis J, Jackson AU et al. Genetic variation in GIPR influences the glucose and insulin responses to an oral glucose challenge. Nature Genetics 201042 142-148. (doi:10.1038/ng.521)

19 Voight BF, Scott LJ, Steinthorsdottir V, Morris AP, Dina C, Welch RP, Zeggini E, Huth C, Aulchenko YS, Thorleifsson G et al. Twelve type 2 diabetes susceptibility loci identified through largescale association analysis. Nature Genetics 201042 579-589. (doi:10.1038/ng.609)

20 Soranzo N, Sanna S, Wheeler E, Gieger C, Radke D, Dupuis J, Bouatia-Naji N, Langenberg C, Prokopenko I, Stolerman E et al. Common variants at 10 genomic loci influence hemoglobin A1(C) levels via glycemic and nonglycemic pathways. Diabetes 201059 3229-3239. (doi:10.2337/db10-0502)

21 Frayling TM, Timpson NJ, Weedon MN, Zeggini E, Freathy RM, Lindgren CM, Perry JR, Elliott KS, Lango H, Rayner NW et al. A common variant in the FTO gene is associated with body mass index and predisposes to childhood and adult obesity. Science 2007 316 889-894. (doi:10.1126/science.1141634)

22 Saxena R, Elbers CC, Guo Y, Peter I, Gaunt TR, Mega JL, Lanktree MB, Tare A, Castillo BA, Li YR et al. Large-scale genecentric meta-analysis across 39 studies identifies type 2 diabetes loci. American Journal of Human Genetics 201290 410-425. (doi:10.1016/j.ajhg.2011.12.022)

23 Morris AP, Voight BF, Teslovich TM, Ferreira T, Segrè AV, Steinthorsdottir V, Strawbridge RJ, Khan H, Grallert H, Mahajan A et al. Large-scale association analysis provides insights into the genetic architecture and pathophysiology of type 2 diabetes. Nature Genetics 2012 44 981-990. (doi:10.1038/ng.2383)

24 Stancáková A, Kuulasmaa T, Paananen J, Jackson AU, Bonnycastle LL, Collins FS, Boehnke M, Kuusisto J \& Laakso M. Association of 18 confirmed susceptibility loci for type 2 diabetes with indices of insulin release, proinsulin conversion, and insulin sensitivity in 5,327 nondiabetic Finnish men. Diabetes 200958 2129-2136. (doi:10.2337/db09-0117)

25 Stancáková A, Javorský M, Kuulasmaa T, Haffner SM, Kuusisto J \& Laakso M. Changes in insulin sensitivity and insulin release in relation to glycemia and glucose tolerance in 6,414 Finnish men. Diabetes 200958 1212-1221. (doi:10.2337/db08-1607)

26 Vlassi M, Gazouli M, Paltoglou G, Christopoulos P, Florentin L, Kassi G \& Mastorakos G. The rs10830963 variant of melatonin receptor MTNR1B is associated with increased risk for gestational diabetes mellitus in a Greek population. Hormones $20121170-76$.

27 Liao S, Liu Y, Tan Y, Gan L, Mei J, Song W, Chi S, Dong X, Chen X \& Deng S. Association of genetic variants of melatonin receptor $1 \mathrm{~B}$ with gestational plasma glucose level and risk of glucose intolerance in pregnant Chinese women. PLoS ONE 20127 e40113. (doi:10.1371/journal.pone.0040113)

28 Mulder H, Nagorny CLF, Lyssenko V \& Groop L. Melatonin receptors in pancreatic islets: good morning to a novel type 2 diabetes gene. Diabetologia 200952 1240-1249. (doi:10.1007/ s00125-009-1359-y)

29 Sladek R, Rocheleau G, Rung J, Dina C, Shen L, Serre D, Boutin P, Vincent D, Belisle A, Hadjadj S et al. A genome-wide association study identifies novel risk loci for type 2 diabetes. Nature 2007 445 881-885. (doi:10.1038/nature05616)

30 Lauenborg J, Grarup N, Damm P, Borch-Johnsen K, Jørgensen T, Pedersen $\mathrm{O} \&$ Hansen T. Common type 2 diabetes risk gene variants associate with gestational diabetes. Journal of Clinical Endocrinology and Metabolism 200994 145-150. (doi:10.1210/ jc.2008-1336)

31 Shaat N, Lernmark A, Karlsson E, Ivarsson S, Parikh H, Berntorp K \& Groop L. A variant in the transcription factor 7-like 2 (TCF7L2) gene is associated with an increased risk of gestational diabetes mellitus. Diabetologia $2007 \mathbf{5 0} 972-979$. (doi:10.1007/s00125-007-0623-2)

32 Saxena R, Gianniny L, Burtt NP, Lyssenko V, Giuducci C, Sjögren M, Florez JC, Almgren P, Isomaa B, Orho-Melander M et al. Common single nucleotide polymorphisms in TCF7L2 are reproducibly associated with type 2 diabetes and reduce the insulin response to glucose in nondiabetic individuals. Diabetes 200655 2890-2895. (doi:10.2337/db06-0381)

33 Villamor E \& Cnattingius S. Interpregnancy weight change and risk of adverse pregnancy outcomes: a population-based study. Lancet $2006 \mathbf{3 6 8} 1164-1170$. (doi:10.1016/S0140-6736(06) 69473-7)

34 Baerenwald DA, Bonnefond A, Bouatia-Naji N, Flemming BP, Umunakwe OC, Oeser JK, Pound LD, Conley NL, Cauchi S, Lobbens S et al. Multiple functional polymorphisms in the G6PC2 gene contribute to the association with higher fasting plasma glucose levels. Diabetologia 201356 1306-1316. (doi:10.1007/ s00125-013-2875-3)

35 Sparsø T, Andersen G, Nielsen T, Burgdorf KS, Gjesing AP, Nielsen AL, Albrechtsen A, Rasmussen SS, Jørgensen T, BorchJohnsen K et al. The GCKR rs780094 polymorphism is associated with elevated fasting serum triacylglycerol, reduced fasting and OGTT-related insulinaemia, and reduced risk of type 2 diabetes. Diabetologia 200851 70-75. (doi:10.1007/s00125-007-0865-z)

36 Ingelsson E, Langenberg C, Hivert MF, Prokopenko I, Lyssenko V, Dupuis J, Mägi R, Sharp S, Jackson AU, Assimes TL et al. Detailed physiologic characterization reveals diverse mechanisms for novel genetic Loci regulating glucose and insulin metabolism in humans. Diabetes 201059 1266-1275. (doi:10.2337/db091568)

Received 4 April 2013

Revised version received 21 May 2013

Accepted 6 June 2013 